\title{
Empirical Study on the Interaction between the Industry-University-Research Collaboration and the Innovative City Construction
}

\author{
Huining Jin $^{1,}$, Jie Duan, ${ }^{2, b}$ and Hailin Bai ${ }^{3, c}$ \\ ${ }^{123}$ School of Humanities, Economics and Law, Northwestern Polytechnical University, \\ Shaanxi, Xi'an 710129, China.

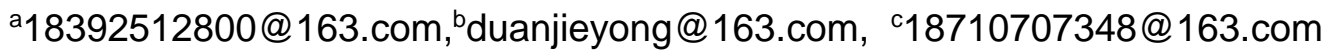

\begin{abstract}
Keywords: Industry-University-Research Collaboration, Innovative City Construction, Interaction, Information Entropy.

Abstract. The industry-university-research collaboration is the driving force for the innovative city construction. The innovative city construction can promote the development of the industry-university-research collaboration. This article empirically studies the interaction between industry-university-research cooperation and innovative city construction by introducing information entropy and combining the actual status quo of Xi'an, in order to make up for the lack of theoretical research. The results showed that the interaction between the two has been increasing year by year, but the interaction intensity is low.It is necessary to continue to strengthen investment in innovative activities.
\end{abstract}

\section{Introduction}

In theory, there is a strong interaction between the industry-university-research cooperation and the innovative city construction. The innovative city construction needs to have sufficient scientific and technological innovation capabilities, which is an inexhaustible motive force for the continuous improvement of social productivity. The basic subjects of basic science and technology innovation are universities, research centers, and the basic subjects of applied technology innovation are enterprises. Establishing a three-spiral cooperative relationship between universities, research institutes and enterprises will be conducive to strengthening technological innovation, raising the level of economic development and promoting the construction of innovative cities. In addition, the demand for innovative city construction will promote the exchange of universities, research institutions and enterprises, and promote the industry-university-research cooperation.

There is no direct study of the interaction between industry-university-research cooperation and innovative city construction. According to the pilot time for the innovative city construction in Xi'an and the theoretical research of scholars, this study uses the relevant data from 2010 to 2016, and empirically studies the interaction between industry-university-research cooperation and innovative city construction by introducing information entropy.

\section{Interactive analysis}

Talent Interaction. The industry-university-research cooperation will strengthen the links between enterprises and universities and increase the number of technical exchange activities and cooperation. The industry-university-research cooperation will cultivate more innovative talents for the society, who contribute to the innovative city construction. The innovative city construction will need innovative talent resources, which will encourage the society to pay attention to personnel training, attract a large number of high-tech technical talents and management elites, and promote joint training programs for talents between universities and universities. At the same time, they will strengthen the transformation of scientific and technological achievements in the way of industry-university-research cooperation, and improve the overall level of innovation in city. 
Knowledge Innovation Interaction. Knowledge innovation is the result of the industry-university-research cooperation, and is also the driving force behind the promotion of innovative cities.Enterprises, universities and scientific research institutions carry out knowledge innovation through the industry-university-research cooperation,transform knowledge innovation into technological production innovation. It will improve the overall innovation capability of the city and accelerate the innovative city construction. At the same time, the high requirements of the innovative city construction will encourage companies to strengthen the cooperation with research institutes and strengthen the Knowledge Innovation Efficiency.

Innovation Platform Interaction. Innovation platform interaction is the environmental basis for the industry-university-research cooperation, which creates a good environment for the innovative city construction. Through technology innovation alliances, university science parks and technology transfer centers, universities can establish technical cooperation with enterprises, and successfully complete the industrial production of technological achievements. A good innovation environment in universities will improve the overall level of innovation and promote the innovative city construction.

\section{Empirical Analysis}

Indicator Selection. According to the interaction between industry-university-research cooperation and innovative city construction, as well as the selection of relevant indicators in the literature, this study selects the indicators to indicate the status of the industry-university-research cooperation and the development of innovative city in Xi'an, and build an innovative evaluation system to reflect the overall innovation capability and level in Xi'an.This article uses objective valuation methods, determines the index weights, and evaluates the effectiveness of the innovative interactive system composed of the industry-university-research cooperation and innovative city construction in Xi'an.

Establish a Matrix between the Indicators. In this paper, the innovation evaluation system has four first-level indicators and twenty-six third-level indicators, and there are seven evaluation targets. Therefore, there are 26 evaluation indicators for each evaluation target, the judgment matrix $\mathrm{Y}=\left(\mathrm{y}_{\mathrm{ij}}\right) \mathrm{m}^{*} \mathrm{n}(\mathrm{i}=1,2,3 \ldots 7 ; \mathrm{j}=1,2,3 \ldots 26), \mathrm{m}=7, \mathrm{n}=26$. According to the indicator data, the judgment matrix $\mathrm{Y}$ is the following Figure 1.

\begin{tabular}{|c|c|c|c|c|c|c|}
\hline 67708 & 78636 & 81787 & 88179 & 101479 & 117176 & 130909 \\
\hline 128559 & 147814 & 162232 & 161004 & 173320 & 160629 & 188267 \\
\hline 1672712 & 2025288 & 2294743 & 2567704 & 2871157 & 3037122 & 3255583 \\
\hline 1031223 & 1322923 & 1768282 & 1926100 & 3125766 & 3841817 & 4484185 \\
\hline 255.57 & 266.51 & 350.88 & 432.38 & 601.01 & 615.33 & 653.58 \\
\hline 5.11 & 6.49 & 8.18 & 13.26 & 14.5 & 16.71 & 18.31 \\
\hline $5.16 \%$ & $5.23 \%$ & $5.22 \%$ & $5.21 \%$ & $5.23 \%$ & $5.24 \%$ & $5.18 \%$ \\
\hline 672 & 774 & 690 & 802 & 878 & 1008 & 1034 \\
\hline 358 & 1546 & 1631 & 1684 & 1777 & 1805 & 1967 \\
\hline 35 & 35 & 40 & 50 & 55 & 55.13 & 57.27 \\
\hline 4465 & 4907 & 6123 & 6647 & 6285 & 6522 & 6957 \\
\hline 1461804 & 1841027 & 2023059 & 2670473 & 2779458 & 2899714 & 3358343 \\
\hline 14230800 & 16141463 & 18035397 & 21606662 & 20253157 & 17669953 & 17395026 \\
\hline 530805 & 745310 & 1000419 & 1135398 & 1115171 & 1183865 & 1196292 \\
\hline 43550 & 52192 & 59301 & 78976 & 134866 & 254413 & 274783 \\
\hline $14.28 \%$ & $15.07 \%$ & $16.74 \%$ & $15.56 \%$ & $13.61 \%$ & $12.91 \%$ & $12.69 \%$ \\
\hline $1.17 \%$ & $1.06 \%$ & $0.99 \%$ & $1.08 \%$ & $1.65 \%$ & $2.77 \%$ & $2.92 \%$ \\
\hline 3130.15 & 3552.21 & $4066 \quad .31$ & $4436 \quad .57$ & $4961 \quad .12$ & $4924 \quad .57$ & 5266.25 \\
\hline 1.74 & 1.80 & 1.87 & 1.94 & 2.06 & 2.13 & 2.54 \\
\hline 38357 & 45561 & 51499 & 57464 & 63794 & 66938 & 71647 \\
\hline 4951265 & 6447050 & 6591977 & 7880206 & 9488010 & 12141353 & 85059382 \\
\hline 1707925 & 2224850 & 2905877 & 3539526 & 3896038 & 4101017 & 4590772 \\
\hline 12140 & 13680 & 15196 & 17751 & 18914 & 20582 & 22503 \\
\hline 8037 & 9274 & 11862 & 16250 & 17271 & 25103 & 38279 \\
\hline 18107 & 12278 & 12120 & 8850 & 8875 & 9600 & 35391 \\
\hline 26814 & 26433 & 28155 & 30627 & 34898 & 32239 & 39593 \\
\hline
\end{tabular}

Fig. 1 The judgment matrix Y 
Normalize the Judgment Matrix Y. Normalize the judgment matrix $Y$ to obtain the matrix $b=\frac{\mathrm{y}_{\mathrm{ij}}-y_{\min }}{y-y}$

B: $\quad y_{\max }-y_{\text {min }},(i=1,2,3 \ldots 7 ; j=1,2,3 \ldots 26)$, where $y_{\max }$ represents the maximum of sever objects that were evaluated for an indicator, $y_{\min }$ represents the minimum of sever objects that were evaluated for an indicator.

Determine the Entropy of Each Indicator. The entropy of each indicator is defined as: $\mathrm{e}_{j}=k \sum_{i=1}^{7} p_{i j} \ln p_{i j},(\mathrm{i}=1,2,3 \ldots 7 ; \mathrm{j}=1,2,3 \ldots 26), 0 \leq \mathrm{e}_{j} \leq 1,{ }^{k=-\frac{1}{\ln m}}, \mathrm{~m}=7$, this article defines the modified matrix $\mathrm{B}$ as a matrix $\mathrm{P}$ :$$
\mathrm{p}_{i j}=\frac{1+b_{i j}}{\sum_{i=1}^{7}\left(1+b_{i j}\right)}
$$

Then, based on the correction matrix $\mathrm{P}$, obtain the vector a of the entropy of each indicator, $\mathrm{a}=$ (0.987, 0.990, 0.988, 0.984, 0.982, 0.985, 0.988, 0.984, 0.991, 0.981, 0.987, 0.988, 0.989, 0.988, 0.980, 0.986, 0.978, 0.987, 0.987, 0.988, 0.982, 0.987, 0.987, 0.986, 0.983, 0.985).

The difference coefficient of each indicator is: ${ }^{h}{ }_{j}=1-e_{j}, j=1,2,3 \ldots 26$.

The vector $b$ of the difference coefficient is that: $b=(0.013,0.010,0.012,0.016,0.018,0.015$, $0.012,0.016,0.009,0.019,0.013,0.012,0.011,0.012,0.020,0.014,0.022,0.013,0.013,0.012,0.018$, $0.013,0.013,0.014,0.017,0.015)$.

Determine Objective Weights. The objective weights $w_{j}$ of each indicator is obtained by the entropy method, $\quad \mathrm{w}_{j}=\frac{h_{j}}{\sum_{j=1}^{26} h_{j}},(\mathrm{j}=1,2,3 \ldots 26), \sum_{j=1}^{26} w_{j}=1$. The objective weight vector $\mathrm{c}=(0.036,0.026$, 0.033, 0.042, 0.048, 0.041, 0.032, 0.043, 0.025, 0.051, 0.034, 0.033, 0.029, 0.033, 0.054, 0.038, 0.057, $0.034,0.035,0.033,0.049,0.034,0.035,0.039,0.044,0.040)$.

Determine Comprehensive Evaluation of System Effectiveness. The overall value is $\mathrm{y}=\sum_{j=1}^{26} w_{j} p_{i j},(\mathrm{i}=1,2,3 \ldots 7 ; \mathrm{j}=1,2,3$

, 3...26). The evaluation result is calculated as the following Table 1:

Table 1 Comprehensive evaluation value of Innovation system effectiveness

\begin{tabular}{cccccccc}
\hline Year & 2010 & 2011 & 2012 & 2013 & 2014 & 2015 & 2016 \\
\hline $\begin{array}{c}\text { Comprehensive } \\
\text { Evaluation Value }\end{array}$ & 0.1028 & 0.1160 & 0.1280 & 0.1417 & 0.1549 & 0.1667 & 0.1901 \\
\hline
\end{tabular}

\section{Conclusions}

Firstly, through the above series of indicator data, it can be seen that since 2010, the industry-university-research collaboration in Xi'an has been continuously strengthened, and the investment in scientific research funds and talents in universities has been significantly improved. The expenditures on financial science and technology have increased by more than six times in seven years.It can be seen that the government's investment in science and technology has been continuously increasing. The transaction volume of the entire technology market has also been gradually increasing, the transformation rate of scientific and technological achievements has been significantly improved, and the effect of technology patented products has been significant; The total industrial output value of the high-tech industry has accounted for $30.44 \%$ of the total industrial output value in 2016, the output value of new industrial products is also gradually increasing, the export value of high-tech enterprises and the number of authorized patents of enterprises and institutions have all been greatly improved. The level of science and technology has been improved and the overall innovation capacity has been significantly enhanced, which provides a good momentum and a foundation for the innovative city construction.

Secondly, Through the empirical analysis results, it can be seen that from 2010 to 2016, the comprehensive evaluation value of the Xi'an innovation index evaluation System constructed by the industry-university-research collaboration and the innovative city construction have been increasing 
year by year, increasing year by year from 0.1028 in 2010 to 0.1901 in 2016 , which indicates that the interaction between the two is continuously increasing, and the entire innovation system is developing in a good direction. The maximum value of the comprehensive evaluation result of the innovation index evaluation system is 1 , and the closer to 1 , the stronger the interactive effect of the system. However, from this article, we can see that the comprehensive evaluation value of system effectiveness is obviously low, the maximum value is less than 0.2 , and the annual growth rate is small. It can be concluded that the current interactive system of innovation in Xi'an is not yet perfect, and the interactive effect of the industry-university-research collaboration and the innovative city construction needs to be further improved. The cooperation mechanism, government management mechanism, and the resource sharing mechanism needs further improvement.

Third, to achieve the goal of building an innovative city, Xi'an still needs to strengthen the deep integration between the government, universities, research institutes and enterprises, provide scientific research funds and scientific research projects for universities and research institutions, encourage scientific researchers to conduct scientific research. Through tax incentives policies, Xi'an can guide companies in adopting new technologies and new methods, constantly changing production methods, increasing production efficiency and production quality; Through the technology transfer centers and technology transfer networks, the implementation channels for technology transfer will be perfected so that industrialized technologies will be commercially produced, the cooperation intensity and cooperation depth between school-enterprise cooperation partners will be improved, and the consistent supply and demand of science and technology will be fully realized. The industry-university-research collaboration will become a edge for the innovative city construction, providing an steady stream of momentum and support for the development of innovation in Xi'an.

\section{Acknowledgements}

Thanks for following Funds, Xi'an Science and Technology Program Soft Science Project (2016040/RK03(6)), Sponsored by the Seed Fundation of Innovation and Creation for Graduate students in Northwestern Polytechnical University(ZZ2018215).

\section{References}

[1] Liu Wei, Ma Wencong, Fan Xia. Research on the Interaction between the Industry-University-Research Cooperation and Internal R\&D in Enterprises--Based on the Perspective of Enterprise's Technological Capability Evolution[J]. Studies in Science of Science, 2012(12): 1853-1861.

[2] Yu Menghui. Research on interaction theory of Industry-University-Research Cooperation and Regional Economic Development[J]. Chinese University Technology Transfer, 2014(12): 50-51.

[3] Qu Hong, Shan Yuyuan.Research on the Interactive Development Mechanism of Industrial Cluster Upgrading and Innovative City Construction[J]. Seeker, 2007(9): 11-12.

[4] Zheng Hongdan. Research on the interaction mechanism between modern information industry and innovative city[D]. Beijing Jiaotong University, 2009.

[5] Zhao Qing. Analysis of the Interaction between University Development and Innovative City Construction[J]. Journal of Beijing Jiaotong University(Social Sciences Edition), 2010, 9(2): 91-95.

[6] Ma Youcai, Zhao Yingchao, Yang Yang.Interactive Development of High-tech Industrial Clusters and Innovative City Construction: Based on System Dynamics[J]. Science \& Technology Progress and Policy, 2010, 27(18): 50-53.

[7] Su Changqing. Research on the Interactive Development Mechanism of Innovative Industrial Clusters and Innovative Cities[J]. Academic Journal of Zhongzhou, 2011(6): 55-57. 
[8] Li Yan. Research on the Interaction Mechanism between the Development of High-tech Industries and the Innovative City Construction[D]. Wuhan University of Technology, 2013. 